\title{
The Effects of Several Types of Induced Abiotic Stress on Cephalaria joppensis Germination under Controlled Conditions
}

\author{
Miriam Daklo-Keren', Waffa Abu-Aklin', Orit Cohen1, Valantina Berger', Galina Sidan', \\ Aharon Bellalou², Orit Amir-Segev², Ran Hovav², Shmuel Galili2*
}

${ }^{1}$ Seed Laboratory, Institute of Plant Sciences, Agricultural Research Organization, The Volcani Center, Rishon Le Ziyyon, Israel ${ }^{2}$ Vegetables \& Field Crops Science Department, Institute of Plant Sciences, Agricultural Research Organization, The Volcani Center, Rishon Le Ziyyon, Israel

Email: ^galilis@volcani.agri.gov.il

How to cite this paper: Daklo-Keren, M., Abu-Aklin, W., Cohen, O., Berger, V., Sidan, G., Bellalou, A., Amir-Segev, O., Hovav, R. and Galili, S. (2018) The Effects of Several Types of Induced Abiotic Stress on Cephalaria joppensis Germination under Controlled Conditions. American Journal of Plant Sciences, 9, 1486-1499. https://doi.org/10.4236/ajps.2018.97109

Received: April 9, 2018

Accepted: June 22, 2018

Published: June 25, 2018

Copyright (C) 2018 by authors and Scientific Research Publishing Inc. This work is licensed under the Creative Commons Attribution International License (CC BY 4.0).

http://creativecommons.org/licenses/by/4.0/

\begin{abstract}
The recently domesticated species, Cephalaria joppensis (CJ), is emerging as a new alternative forage crop in Israel. It has high biomass potential and nutritional values that are comparable to forage wheat. However, CJ emerges slowly under cold conditions, which hinders its development as a major winter crop. Additional tolerance for abiotic stress would improve its performance as a forage crop. We examined the effects of several abiotic factors (i.e., cold, salinity, drought and $\mathrm{pH}$ ) on $\mathrm{CJ}$ germination under controlled conditions. The effect of temperature was studied by incubating seeds at different temperatures between $7{ }^{\circ} \mathrm{C}$ and $35^{\circ} \mathrm{C}$. The effects of salinity, osmotic potential and $\mathrm{pH}$ were tested by incubating seeds at different $\mathrm{NaCl}$, PEG and pH levels, respectively. Temperature, salinity and osmotic potential significantly affected germination; whereas $\mathrm{pH}$ did not. Temperature did not affect the final proportion of germinated seeds, but did affect other germination-rate variables, indicating that germination rate might be the limiting factor under field conditions. Salinity also affected germination-rate variables, but not the proportion of seeds that germinated. Notably, CJ was found to be relatively resistant to high salt concentrations, with a $273 \mathrm{mM} \mathrm{NaCl}$ threshold for germination, indicating its potential as a relatively salt-tolerant forage crop. Both the proportion of germinated seeds and the germination rate were highly sensitive to the osmotic-potential treatments, indicating that drought resistance will remain the biggest challenge for CJ. This study provides baseline data for a rapid and efficient system for further screening for abiotic-stress tolerance among wild and cultivated lines of CJ.
\end{abstract}




\section{Keywords}

Cephalaria joppensis, Abiotic Stress, Seed Germination

\section{Introduction}

Wheat constitutes a significant component of the silage and forage grown in Mediterranean regions. In Israel, for example, wheat accounts for about $50 \%$ of forage production [1]. Yet, grown as a winter crop without additional irrigation, wheat forage has several disadvantages, including relatively low yields (10 - 14 dry tons/ha) [1] [2] [3], farmers' preference for growing wheat for grain instead of forage and an acute shortage of lands for crop rotation. As a result, in recent years, there has been a shortage of local rough forage for livestock. One possible solution is the development of alternative high-yielding winter crops that would improve the profitability of forage-oriented agricultural production and could be incorporated into better crop-rotation systems.

Cephalaria joppensis (CJ), whose domestication was recently initiated [4], is a promising complementary crop for wheat silage. CJ has many advantages relative to other broad leaf rotation crops (e.g., forage legumes). It is very easy and inexpensive to grow, naturally resistant to many pests and has high yield potential. In addition, its nutritional quality is equivalent to that of wheat and there is little accumulation of nitrites in the silage [4] [5]. This crop is harvested relatively late in the spring season and does not need to dry out in the field before ensiling. Initial observations have identified CJ as a very good fallow crop (Galili, personal observation).

Nevertheless, several factors limit the promotion of this species. CJ is sensitive to most existing commercial herbicides, and it grows relatively slowly in the colder weather of the winter; it begins to grow rapidly only in the early spring. These two characteristics make weed management in this crop particularly challenging, since the competing weeds grow faster than the crop under cold conditions. Drought is another important factor that hinders the expansion of $\mathrm{CJ}$ cultivation. The only existing commercial variety, "Rishon", performs poorly under drought conditions and, therefore, is not grown in areas with less than $350 \mathrm{~mm}$ of annual precipitation. Indeed, the need for more drought-tolerant varieties is becoming increasingly critical in light of the increased desertification around the world [6].

In many dry and semi-arid regions, slightly saline water from deep wells is being used for crop irrigation. This can lead to reductions in crop fitness and production due to salinity, as well as to severe accumulation of salts in the soil. One possible solution is the development of new salt-resistant cultivars. Wild CJ maybe considered naturally resistance to salt stress, since several accessions have been collected from very salty soils and seaside sites (Galili, personal observation). Yet, the direct effects of salinity on CJ germination and growth have not 
been previously studied.

Genetic and agronomic improvements that include the introduction of herbicide resistance and increased plant vigor and crop uniformity under stressful conditions could help CJ to become a leading forage crop in rotation systems. In this study, we examined the effects of temperature, salt, osmotic potential and $\mathrm{pH}$ on CJ seed germination under controlled conditions. This work is part of an effort to develop new tools for screening for abiotic-stress resistance among wild and developed lines of CJ. Although they concern only one aspect of plant development (i.e., germination), our results serve as the first indications of CJ's responses to abiotic-stress conditions and may serve as a baseline for future breeding/selection work.

\section{Materials and Methods}

\subsection{Plant Material}

CJ seeds, cv. Rishon, were used for this study. We sterilized the seeds by immersing them in $1 \%$ bleach for $30 \mathrm{~min}$ and then rinsing them five times in distilled water. The seeds were dried in a sterile laminar hood and then kept at room temperature until they were used.

\subsection{Stress Experiments}

Each experiment was performed in six replications with 25 seeds each. To that end, 50 sterilized seeds were placed on two-layer germination paper using a vacuum plate. The paper's surface was divided into two areas, each containing 25 seeds. The seeds were covered with additional wet germination paper and the papers were rolled into cylinders, placed inside polyethylene bags (three cylinders per bag) and covered with aluminum foil to prevent light penetration. For the temperature experiment, the cylinders were incubated for 2 weeks at $7^{\circ} \mathrm{C}$, $10^{\circ} \mathrm{C}, 12^{\circ} \mathrm{C}, 15^{\circ} \mathrm{C}, 20^{\circ} \mathrm{C}, 25^{\circ} \mathrm{C}, 30^{\circ} \mathrm{C}$ and $35^{\circ} \mathrm{C}$ (three cylinders at each temperature). During this period, the germination rate was determined every day by counting the number of seeds with $>2 \mathrm{~mm}$ radicles. At the end of the 2 weeks, the length, fresh weight and dry weight (after 3 days at $65^{\circ} \mathrm{C}$ ) were determined for each seedling in each replication.

The salinity experiment used the same design described above, with six replications, but salt solutions were used instead of regular water. Five salt concentrations were used with concentrations of: $0 \mathrm{mM}$ (distilled water), $40 \mathrm{mM}, 80$ $\mathrm{mM}, 120 \mathrm{mM}$ and $160 \mathrm{mM} \mathrm{NaCl}$. For the osmotic-potential experiment, the same design was used, but the cylinders were placed in polyethylene glycol (PEG) solutions at $0 \mathrm{Mpa}$ (control), $0.1 \mathrm{Mpa}, 0.2 \mathrm{Mpa}, 0.4 \mathrm{Mpa} 0.8 \mathrm{Mpa}$ and 1 Mpa.PEG 6000 (Duchefa; Netherlands) was used with a specific formula, as described by [7]. For the $\mathrm{pH}$ experiment, nine $\mathrm{pH}$ levels (i.e., 4 - 11) were tested and tap water ( $\mathrm{pH}$ 6.8) was used as a control. The $\mathrm{pH}$ solutions were prepared as described by [8]. In all three experiments, the paper cylinders were incubated in the dark at $25^{\circ} \mathrm{C}$ for 10 days. At the end of the incubation period, we measured 
the length, fresh weight and dry weight of each seedling.

\subsection{Calculation of Germination Variables}

The percentage of seeds that germinated $(\% G)$ was determined using the following formula:

$$
\% G=\frac{100 * \text { number of germinated seeds }}{\text { Total number of seeds }}
$$

Germination index $(G I)$, the estimated germination rate of the seeds, was calculated using this formula:

$$
G I(\text { seed/day })=\sum_{d=1}^{n} \frac{\text { number of germinated seeds at Day } d}{d}
$$

In that formula, $d$ is the number of days from the initiation of the experiment.

The mean germination time ( $M G T)$ was calculated using the following formula:

$$
M G T(\text { days })=\frac{\left(\sum_{d=1}^{n} \text { number of germinated seeds at Day } d\right) \times d}{\text { Total number of germinated seeds }}
$$

The seed vigor index $(S V)$ was calculated as follows:

$$
S V=\text { mean seed length } \times \% G
$$

To calculate the point at which $50 \%$ of the seeds had germinated, the following formulas were used:

$$
\begin{gathered}
(\text { Hours }) D_{50} H R=\left(24 \times D_{n-1}\right)+\left(24 / G S D_{n}\right) \times\left(T G S / 2-G S D_{n-1}\right) \\
(\text { Days }) D_{50}=D_{50} H R / 24
\end{gathered}
$$

In those formulas, $D_{50}$ is the number of hours or days until $50 \%$ of the seeds had germinated, $D_{n}$ is the Day $n$ from the initiation of the experiment until the total number of germinated seeds exceeded $50 \%$ of the total number of seeds that had germinated by the end of the experiment. GSD is the number of germinated seeds on $D_{n}$ and $T G S$ is the total number of germinated seeds.

The threshold temperature, osmotic potential and salt concentration for germination were calculated as previously described [9]. Statistical analyses were done using the JMP 5.0 software package (SAS Institute Inc., Cary, NC).

\section{Results}

\subsection{The Effect of Ambient Temperature on Seed-Germination Variables}

The effect of ambient temperature on the germination of CJ seeds is shown in Figure 1. As shown in that figure, almost $100 \%$ of the seeds germinated at all of the examined temperatures, with the exception of the $35^{\circ} \mathrm{C}$ treatment, in which the germination rate declined significantly to $40 \%$ (Figure 1(a)). In contrast, the germination index (GI), which represents the change in germination rate, increased significantly from 3.6 seeds/day at $7^{\circ} \mathrm{C}$ to 20.7 seeds/day at $30^{\circ} \mathrm{C}$ (Figure 1(b)). No significant difference in GI was noted between $12^{\circ} \mathrm{C}$ and $15^{\circ} \mathrm{C}$. There 


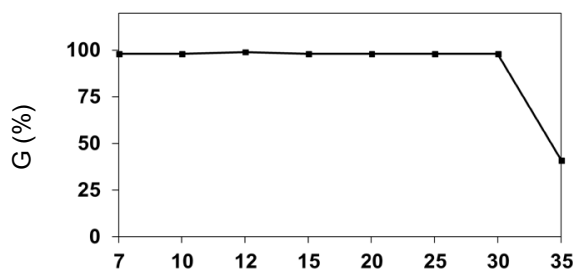

(a)
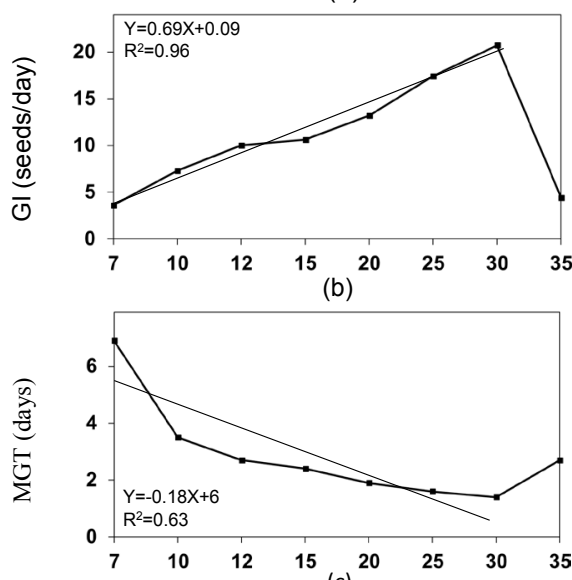

(c)

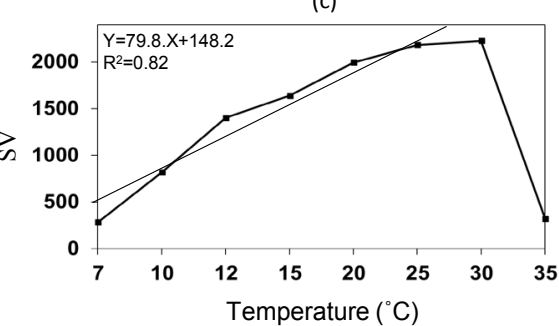

(d)

Figure 1. The effects of temperature on (a) the percentage of seeds that germinated (G); (b) the germination index (GI); (c) mean germination time (MGT); (d) seed vigor (SV); (e) seedling length (SL); (f) seedling fresh weight (SFW) and (g) seedling dry weight (SDW). The graphs show the average values and standard errors for 6 replicates of 25 seeds each. The straight line represents the linear correlation among the temperature treatments.

was a positive linear correlation between $\mathrm{GI}$ and temperature over the $7^{\circ} \mathrm{C}$ $30^{\circ} \mathrm{C}$ range $\left(R^{2}=0.96\right)$. However, increasing the ambient temperature to $35^{\circ} \mathrm{C}$ resulted in a sharp decrease in GI that was significantly different from that observed in all of the other temperature treatments, even the $7^{\circ} \mathrm{C}$ treatment. In contrast, mean germination time (MGT) significantly decreased with the increase in ambient temperature, from 6.9 days at $7^{\circ} \mathrm{C}$ to 1.4 days at $30^{\circ} \mathrm{C}$, with the largest increase seen between $7^{\circ} \mathrm{C}$ and $10^{\circ} \mathrm{C}$ (Figure $1(\mathrm{c})$ ). There was a negative linear correlation between MGT and temperature over the $7^{\circ} \mathrm{C}-30^{\circ} \mathrm{C}$ range $\left(R^{2}\right.$ $=0.63$ ). Increasing the temperature to $35^{\circ} \mathrm{C}$ resulted in a significant increase in MGT, although the MGT at $35^{\circ} \mathrm{C}$ was not significantly different from that observed for the $10^{\circ} \mathrm{C}$ and $12^{\circ} \mathrm{C}$ treatments. Similarly, the germination time for $50 \%$ of the seeds decreased significantly from 4.5 days at $7^{\circ} \mathrm{C}$ to 0.8 days at $30^{\circ} \mathrm{C}$ (data not shown). The germination-threshold temperature was calculated from 
this value and found to be $2.4^{\circ} \mathrm{C}$.

Seed vigor, seedling length and seedling fresh weight all corresponded to GI and were found in positively correlated with temperature $\left(R^{2}\right.$ between 0.82 and 0.83). Seedling vigor increased significantly from 284 at $7^{\circ} \mathrm{C}$ to 2266 at $30^{\circ} \mathrm{C}$ (Figure $1(\mathrm{~d})$ ). Seedling length increased significantly from $2.9 \mathrm{~cm}$ at $7^{\circ} \mathrm{C}$ to 22.7 at $30^{\circ} \mathrm{C}$ (Figure $1(\mathrm{e})$ ) and seedling fresh weight increased significantly from 1.23 $\mathrm{g}$ at $7^{\circ} \mathrm{C}$ to $4.65 \mathrm{~g}$ at $30^{\circ} \mathrm{C}$ (Figure $1(\mathrm{f})$ ). For all of these variables, no significant differences were found between the $25^{\circ} \mathrm{C}$ treatment and the $30^{\circ} \mathrm{C}$ treatment, which both yielded results significantly better than those observed for the $35^{\circ} \mathrm{C}$ treatment. In contrast to seedling fresh weight, seedling dry weight did not vary much between the different temperature treatments (Figure $1(\mathrm{~g})$ ). Since no differences were noted in any of the examined parameters between $25^{\circ} \mathrm{C}$ and $30^{\circ} \mathrm{C}$ (aside from GI), we concluded that this range is the optimum temperature range for the germination of $\mathrm{cv}$. Rishon. Based on that finding, the effects of all of the other types of stress (i.e., salt, PEG, $\mathrm{pH}$ ) were examined at $25^{\circ} \mathrm{C}$.

\subsection{The Effect of Salt Concentration on Seed-Germination Variables}

The effect of $\mathrm{NaCl}$ concentration on the germination of $\mathrm{CJ}$ seeds is described in Figure 2. Similar to the temperature experiments, no difference was found between the salt treatments in terms of $\% \mathrm{G}$ and almost $100 \%$ germination was observed for all of the $\mathrm{NaCl}$ treatments (Figure 2(a)). Unlike \%G, GI was influenced by the salt concertation and significantly decreased from 15.7 seeds/day in distilled water to 6.6 seeds/day in $160 \mathrm{mM} \mathrm{NaCl}$ (Figure 2(b)). There was a significant negative linear correlation between GI and that range of salt concentrations $\left(R^{2}=0.94\right.$; Figure 2(b)). In accordance with that decrease in GI, MGT increased significantly between 1.7 days to 3.7 days, from $0 \mathrm{mM}$ to $160 \mathrm{mM}$, respectively (Figure 2(c)). In addition, the amount of time required for $50 \%$ of the seeds to germinate increased significantly from 1.0 days at $0 \mathrm{mM} \mathrm{NaCl}$ to 3.8 days at $160 \mathrm{mM} \mathrm{NaCl}$ (data not shown). The threshold for osmotic potential was extrapolated from those figures and found to be $273 \mathrm{mM} \mathrm{NaCl}$. Seed vigor, seedling length and seed fresh weight all corresponded to GI and were found to be negatively correlated with $\mathrm{NaCl}$ concentration ( $R^{2}$ between 0.74 and 0.80 ). Seedling vigor significantly decreased from 1459 at $0 \mathrm{mM} \mathrm{NaCl}$ to 501 at $160 \mathrm{~nm}$ $\mathrm{NaCl}$, but no significant differences in seedling vigor were noted between $0 \mathrm{mMNaCland} 40 \mathrm{mM} \mathrm{NaCl}$ (Figure 2(d)). Seedling length decreased significantly from $15.2 \mathrm{~cm}$ at $0 \mathrm{mM}$ to 5.3 at $160 \mathrm{~nm} \mathrm{NaCl}$, but no significant differences in seedling length were noted between $0 \mathrm{mM}$ and $40 \mathrm{mM}$ (Figure 2(e)). Seedling fresh weight decreased significantly from $1.59 \mathrm{~g}$ at $0 \mathrm{mM} \mathrm{NaCl}$ to $0.81 \mathrm{~g}$ at $160 \mathrm{mM} \mathrm{NaCl}$, but no significant differences in seedling fresh weight were noted between $0 \mathrm{mM}$ and $40 \mathrm{mM}$ or $80 \mathrm{mM}$ (Figure 2(f)). As in the temperature experiment, the dry-weight values from the salt experiment did not show any significant change in either direction (Figure $2(\mathrm{~g})$ ). 


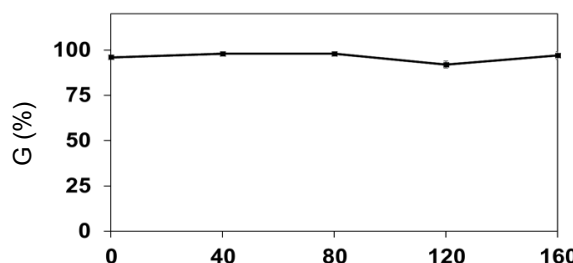

(a)

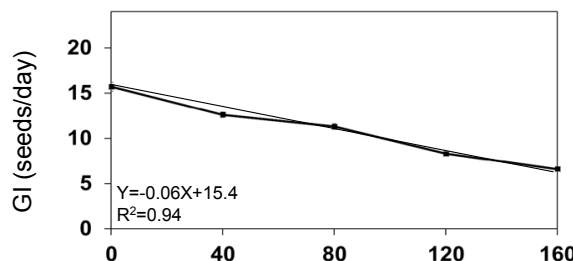

(b)
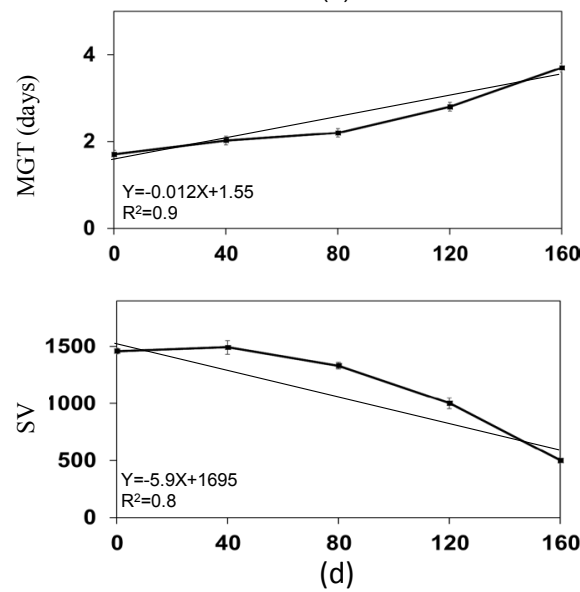

(d)

$\mathrm{NaCl}(\mathrm{mM})$

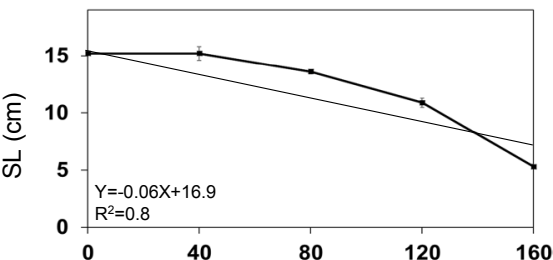

(e)

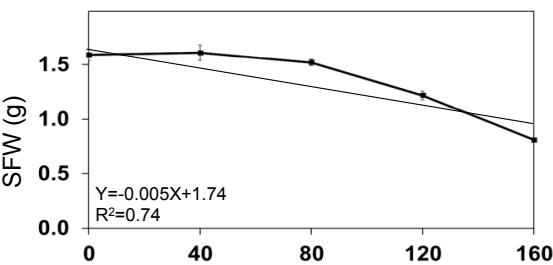

(f)

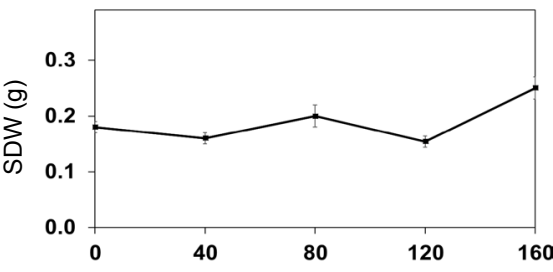

(g)

$\mathrm{NaCl}(\mathrm{mM})$

Figure 2. The effects of different $\mathrm{NaCl}$ concentrations on (a) the percentage of seeds that germinated (G); (b) the germination index (GI); (c) mean germination time (MGT); (d) seed vigor (SV); (e) seedling length (SL); (f) seedling fresh weight (SFW) and (g) seedling dry weight (SDW). The graphs show the average values and standard errors for 6 replicates of 25 seeds each. The straight line represents the linear correlation among the salt treatments.

\subsection{The Effect of Osmotic Potential on Seed-Germination Variables}

The effect of osmotic potential on the germination of $\mathrm{CJ}$ seeds was tested as an indicator of drought tolerance. Different levels of osmotic potential were established through the use of different concentrations of PEG. As shown in Figure 3, the effect of osmotic potential was different from that of salinity, with the exception of $\% \mathrm{G}$. Almost $100 \%$ germination was observed only up to $-0.4 \mathrm{MPa}$ (Figure 3(a)). Beyond that point, $\% \mathrm{G}$ decreased significantly, reaching $79 \%$ at $-0.6 \mathrm{MPa}, 21 \%$ at $-0.8 \mathrm{MPa}$ and $5.6 \%$ at $-1 \mathrm{MPa}$. GI also decreased significantly as the osmotic potential increased, from 15.7 seedlings/day at $0 \mathrm{MPa}$ to 0.2 seedlings/day at $-0.8 \mathrm{MPa}$ (Figure $3(\mathrm{~b})$ ). The negative linear correlation between GI and osmotic potential had an $R^{2}$ value of 0.94 .As expected, a very different trend was observed for MGT. MGT increased significantly as osmotic potential increased, from 1.7 days at $0 \mathrm{MPa}$ to 7.5 days at $-0.8 \mathrm{MPa}$ (Figure 3(c)). 


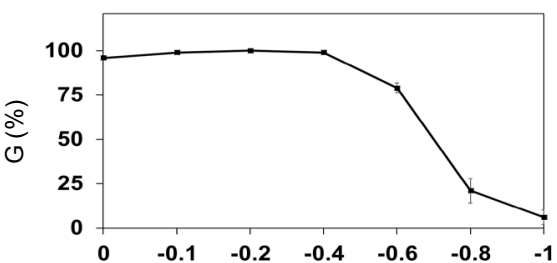

(a)

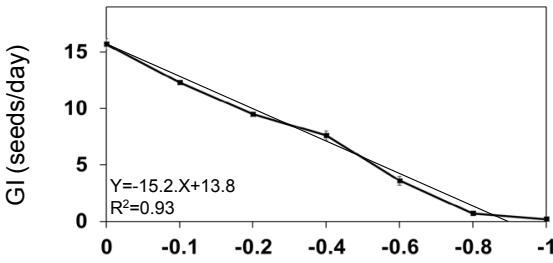

(b)
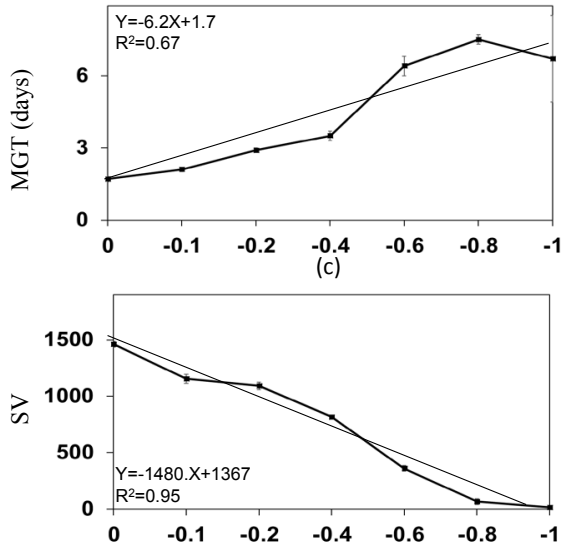

(d)

$\mathrm{MPa}$

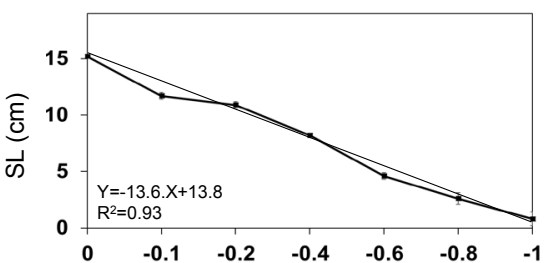

(e)
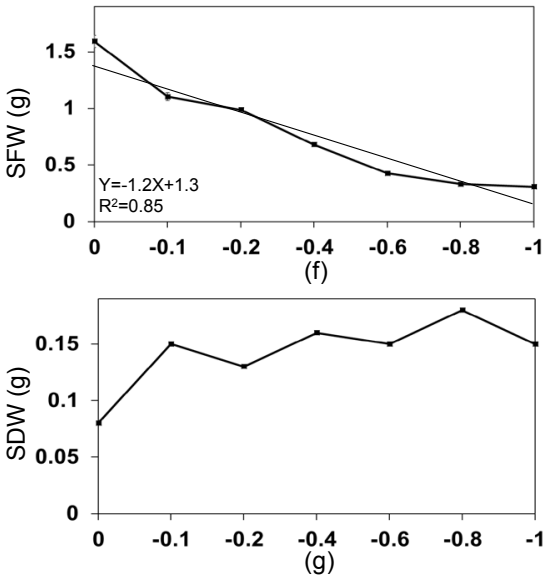

$\mathrm{MPa}$

Figure 3. The effect of osmotic potential on (a) the percentage of seeds that germinated (G); (b) the germination index (GI); (c) mean germination time (MGT); (d) seed vigor (SV); (e) seedling length (SL); (f) seedling fresh weight (SFW) and (g) seedling dry weight (SDW). The graphs show the average values and standard errors for 6 replicates of 25 seeds each. The straight line represents the linear correlation among the osmotic-potential treatments.

In addition, the amount of time required for $50 \%$ of the seeds to germinate increased significantly from 1.3 days at $0 \mathrm{MPa}$ to almost 5 days at $-0.8 \mathrm{MPa}$ (data not shown). The threshold for osmotic potential was extrapolated from those figures and found to be around $-0.95 \mathrm{MPa}$. Significant negative correlations were observed between seed vigor, seedling length and seedling fresh weight, on the one hand, and osmotic potential, on the other, with $R^{2}$ values of $0.95,0.96$ and 0.85 , respectively. Seedling vigor decreased from 1459 at $0 \mathrm{MPa}$ to 13 at -1 $\mathrm{MPa}$ (Figure 3(d)). Seedling length decreased from $15.2 \mathrm{~cm}$ at $0 \mathrm{MPa}$ to $0.8 \mathrm{~cm}$ at $-1 \mathrm{MPa}$ (Figure 3(e)) and seedling fresh weight decreased from $1.59 \mathrm{~g}$ at 0 $\mathrm{MPa}$ to $0.3 \mathrm{~g}$ at -1 . MPa (Figure $3(\mathrm{f})$ ). As osmotic potential increased, a slight increase in seedling dry weight was noted (Figure $3(\mathrm{~g})$ ).

\subsection{The Effect of $\mathrm{pH}$ on Seed-Germination Variables}

These data are presented in Figure 4. As shown, the examined pH levels in this 


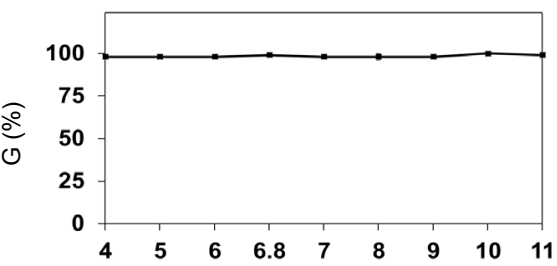

(a)

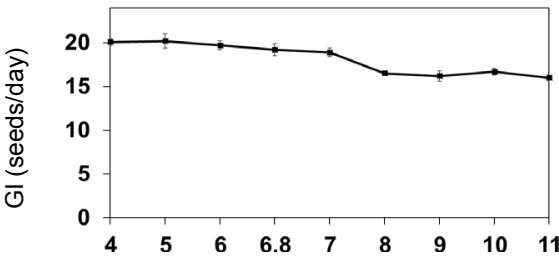

(b)
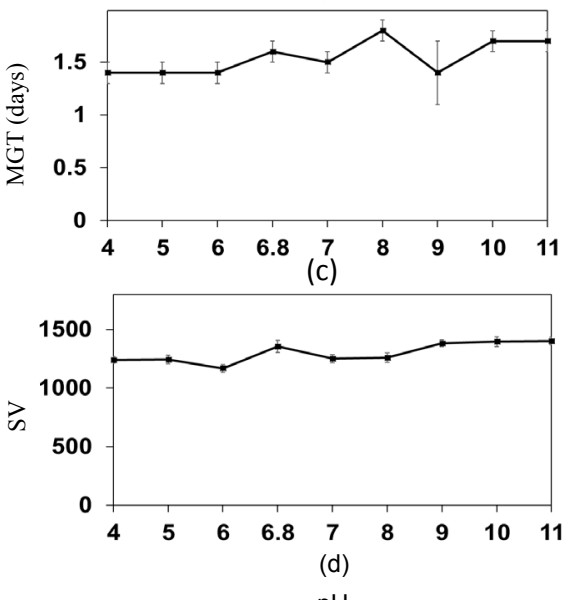

$\mathrm{pH}$

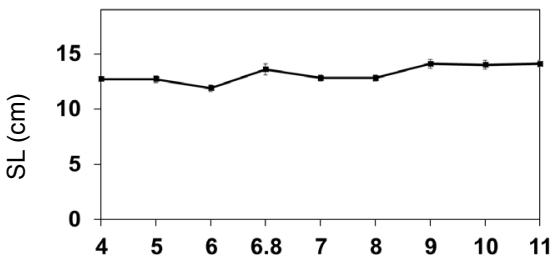

(e)

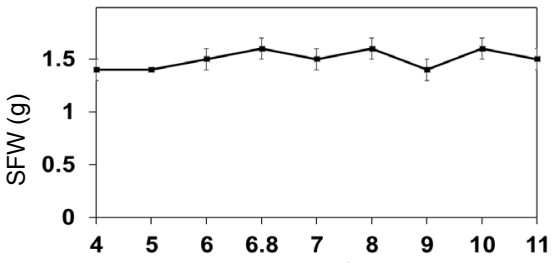

(f)

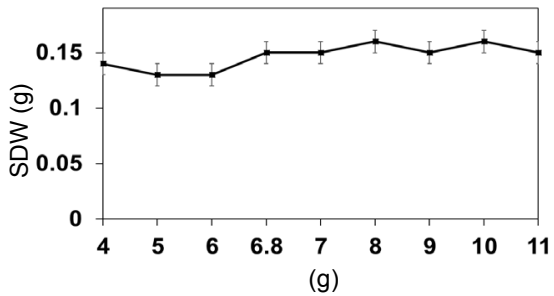

$\mathrm{pH}$

Figure 4. The effect of $\mathrm{pH}$ on (a) the percentage of seeds that germinated (G); (b) the germination index (GI); (c) mean germination time (MGT); (d) seed vigor (SV); (e) seedling length (SL); (f) seedling fresh weight (SFW) and (g) seedling dry weight (SDW). The graphs show the average values and standard errors for 6 replicates of 25 seeds each. The straight line represents the linear correlation among the $\mathrm{pH}$ treatments.

experiment did not influence on the germination of CJ seedlings. Almost 100\% germination occurred in all $\mathrm{pH}$ treatments between $\mathrm{pH}$ 4and $\mathrm{pH} 11$ (Figure 4(a)). Only minor differences in the other germination variables were noted between the $\mathrm{pH}$ treatments (Figures $4(\mathrm{~b})-(\mathrm{g})$ ).

\section{Discussion}

Abiotic stresses such as temperature, drought and salinity decrease agricultural production and are becoming an increasingly important problem [10]. These stresses can delay, reduce or prevent germination [11]. Seed germination could be an efficient stage at which to select abiotic stress-tolerant agricultural crops, since this stage influences the final stand in the field, which strongly affects later stages of crop production [12]. In this study, the effects of several types of abiotic stress on CJ germination were examined for the first time. In general, it was found that the germination of the seedlings of $\mathrm{cv}$. Rishon was affected by temperature, salinity and osmotic potential, but not $\mathrm{pH}$. 
Notably, ambient temperature was not found to affect the final percentage of germinated seeds (almost 100\% of the seeds germinated at all of the examined temperatures). Yet, sharp decrease in all parameters tested except dried weight was observed between $30^{\circ} \mathrm{C}$ and $35^{\circ} \mathrm{C}$. This could be due to that the $35^{\circ} \mathrm{C}$ is above the optimum temperature $\left(25^{\circ} \mathrm{C}-30^{\circ} \mathrm{C}\right)$ for $\mathrm{CJ}$ germination. High temperature might also avoid wild $\mathrm{CJ}$ germination in unexpected early season rainfalls, when temperatures are still high, followed by a long term of dry conditions. Ambient temperature, though, did affect the other germination variables (i.e., GI, seedling vigor, MGT, seedling length and seedling fresh weight). This result indicates that the main problem of $\mathrm{cv}$. Rishon under field conditions is not its germination potential at lower temperatures, but other germination variables. This is also reflected in its relatively low germination-threshold temperature $\left(2.4^{\circ} \mathrm{C}\right)$, which is much lower than the temperatures typical of the Mediterranean autumn (when CJ seeds are sown). It is reasonable to conclude that the reduction in CJ growth during the autumn is due to other variables, which are connected to seedling development as opposed to the initiation of germination. This characteristic of the species can serve as a defense mechanism in the wild, in which the plant is sheltered under the weed canopy during the winter, where it is protected from foraging, and only begins to grow rapidly in the early spring. Interestingly, unlike seedling fresh weight, seedling dry weight was not affected by most of the temperature treatments. This could be due to the fact that the seedlings were germinated in the dark and, therefore, the observed increases in seedling length and seedling fresh weight reflect water absorption as opposed to the accumulation of dry matter. The decrease in seedling dry weight at higher temperatures could be a result of higher respiration rates at those temperatures.

Similar to the results observed from the temperature experiments, no difference was found between salt treatments in terms of \%G; almost 100\% germination was observed at all of the examined $\mathrm{NaCl}$ concentrations. Like temperature, salinity was found to have some effect on germination-rate variables. It is important to note that salt-stress resistance is a trait that is closely associated with development and salinity resistance at a particular phenological stage does not necessarily imply complete resistance throughout the life cycle [13] [14] [15]. However, several studies have indicated that germination and seedling establishment are very crucial stages in the development of salt-sensitive species [16] [17] [18] [19], which affect the total proportion of germinated seeds, the speed at which those seeds germinate and initial plant growth. In Israel, some wild CJ lines have been found very close to the seashore, indicating that there may be some natural variation in salt resistance in this species. Therefore, it is not surprising that the threshold salt concentration was estimated in this study to be $273 \mathrm{mM}$. That value is similar to those found for other forage cereal plants like wheat [20], sorghum [12] [21] and other forage grasses [22] and higher than the values observed for forage legumes such as white clover [23] and alfalfa [24]. As in the temperature experiment, in the salt experiment, there were no significant trends in terms of dry weight (Figure $2(\mathrm{~g})$ ), indicating once again that the dif- 
ferences observed in seedling length and seedling fresh weight were due to the absorption of water by the seedlings grown in the dark.

Drought tolerance is one of the most challenging traits to select in field crops. The biggest difficulty is how to control and repeat field trials [25]. Richards, [26] suggested utilizing the germination stage of seedlings under controlled conditions for selecting for drought tolerance. Khakwani et al. [27], used different methods to evaluate the drought tolerance of six wheat cultivars and identified lines in which there was a strong correlation between the results seen under controlled conditions and the drought resistance observed in the field. Similar results were found in studies involving sweet potato [28]. One way to screen for drought-tolerance under controlled conditions is to use PEG to introduce drought-like stress conditions. Exposure of the germinating seeds to PEG mimics drought conditions, usually without other side effects [29], and this technique has been successfully used for drought-resistance screening in many crops [30].

In this study, the effect of osmotic potential on $\% \mathrm{G}$ was relatively high and significantly decreased $\% \mathrm{G}$ was observed even at $-0.6 \mathrm{MPa}$, with a sharp decline between $-0.6 \mathrm{MPa}$ and $-0.8 \mathrm{MPa}$. Similar results have been reported for other field crops such as corn, canola, barley [31] [32], and chickpea [33]. In addition, the use of an osmotic potential between -0.4 and $-0.8 \mathrm{MPa}$ was suggested in screens for drought stress [34]. The sharp decline in the $\% \mathrm{G}$ below $-0.6 \mathrm{MPa}$ demonstrates that the absence of drought resistance will remain the biggest challenge for the development of abiotic-stress resistance in CJ. Interestingly, $\mathrm{pH}$ was not found to have any effect on the development of CJ seedlings, indicating that $\mathrm{CJ}$ could be growing in both alkaline soils ( $\mathrm{pH}$ ranging from 7 to 9 ) and acidic soils ( $\mathrm{pH}$ ranging from 5.5 to 7). Therefore, $\mathrm{pH}$ is not expected to limit the expansion of CJ cultivation.

\section{Conclusion}

In summary, the current study serves as an excellent baseline for the development of systems for the selection of abiotic-stress tolerance in CJ. For example, according to the results of this experiment, our suggestion is to screen new germplasm for temperature, salt and osmotic stress at $7^{\circ} \mathrm{C}, 160 \mathrm{mM}$ and -0.8 MPa levels, respectively. Recent field screenings of $\sim 40$ wild lines of $\mathrm{CJ}$ have revealed significant variation in plant morphology and maturity (data not presented here). A rapid and efficient selection system is now available for the evaluation of natural and cultivated variation in CJ.

\section{References}

[1] Zuckerman, E. (2011) Forage Crops and Initial Forecast for 2011. MeshekHabakarVehachalav, 350, 54-58.

[2] Miron, J., Raviv, I., Weinberg, Z.G., Bloch, A., Porat, Y., Nahim, E., Miron, D., Yosef, E., Nikbachat, M., Zenou, A., Adin, G., Portnik, Y., Yakobi, S, Chen, Y., Nashaf, C. and Kushnir, U. (2010) Cephalaria-Anew Forage Plant. MeshekHabakarVehachalav, 346, 70-72. 
[3] Miron, J., Raviv, I., Bloch, A., Porat,, Y., Keinan, B., Yosef, E., Nikbachat, M., Zenou, A., Adin, G., Portnik, Y., Yakobi, S., Mizrahi, I. and Kushnir, U. (2011) Cephalaria as a Replacement of Wheat Silage Orhay-Influence on the Milk Yield and Composition. In Proceeding $23^{\text {rd }}$ Annual Meeting of Cattle Sciences, Jerusalem, 21-23 June 2011.

[4] Miron, J., Weinberg, Z.G., Chen, Y., Miron, D., Raviv, Y., Bloch, A. and Kushnir, U. (2012) Novel Use of the Wild Species Cephalaria joppensis for Silage Preparation and Its Nutritive Value for Feeding Lactating Dairy Cows. Journal of Dairy Science, 95, 4501-4509. https://doi.org/10.3168/jds.2011-5086

[5] Leibovich, H., Zenou, A., Yosef, E., Nikbachat, M., Kaadanc, S., Eshtiwi, H., Miron, J., et al. (2013) Digestibility by Lambs and Nutritive Value for Lactating Ewes of a Total Mixed Ration Containing Cephalaria joppensis Silage as Wheat Silage Substitute. Small Ruminant Research, 112, 97-102.

https://doi.org/10.1016/j.smallrumres.2012.12.004

[6] Tuberosa, R. and Salvi, S. (2006) Genomics-Based Approaches to Improve Drought Tolerance of Crops. Trends in Plant Science, 11, 405-412. https://doi.org/10.1016/j.tplants.2006.06.003

[7] Michel, B.E. (1983) Evaluation of the Water Potentials of Solutions of Polyethylene Glycol 8000 both in the Absence and Presence of Other Solutes. Plant Physiology, 72, 66-70. https://doi.org/10.1104/pp.72.1.66

[8] Chauhan, B.S., Gill, G. and Preston, C. (2006) Factors Affecting Seed Germination of Little Mallow (Malvaparviflora) in Southern Australia. Weed Science, 54, 1045-1050. https://doi.org/10.1614/WS-06-067.1

[9] Guillemin, J-P., Gardarin, A., Granger, S., Reibel, C., Munier-Jolain, N. and Colbach, N. (2013) Assessing Potential Germination Period of Weeds with Base Temperatures and Base Water Potentials. Weed Research, 53, 76-87.

https://doi.org/10.1111/wre.12000

[10] Wassmann, R., Jagadish, S.V.K., Heuer, S., Ismail, A. and Redona, E. (2009) Climate Change Affecting Rice Production: The Physiological and Agronomic Basis for Possible Adaptation Strategies. Advances in Agronomy, 101, 59-122. https://doi.org/10.1016/S0065-2113(08)00802-X

[11] Ghorbani, M.J., Ali, S., Moradi, F., Mohammad, S.A., Sanavy, M. and Allahdad, I. (2011) The Role of Phytohormones in Alleviating Salt Stress in Crop Plants. Australian Journal of Crop Science, 6, 726-734.

[12] Nimir, E.A.N., Lu, S., Zhou, G., Ma, B.L., Guo, W. and Wang, Y. (2014) Exogenous Hormones Alleviated Salinity and Temperature Stresses on Germination and Early Seedling Growth of Sweet Sorghum. Agronomy Journal, 106, 2305-2315.

https://doi.org/10.2134/agronj13.0594

[13] Greenway, H. and Munns, R. (1980) Mechanism of Salt Tolerance in Nonhalophytes. Annual Review of Plant Physiology, 31, 149-190. https://doi.org/10.1146/annurev.pp.31.060180.001053

[14] Johnson, D.W., Smith, S.E. and Dobrenz, A.K. (1992) Genetic and Phenotypic Relationships in Response to $\mathrm{NaCl}$ at Different Developmental Stages in Alfalfa. Theoretical and Applied Genetics, 83, 833-838.

[15] Shannon, M.C. (1985) Principles and Strategies in Breeding for Higher Salt Tolerance. Plant and Soil, 89, 227-241. https://doi.org/10.1007/BF02182244

[16] Ayers, A.D. and Hayward, H.E. (1948) A Method for Measuring the Effects of Soil Salinity on Seed Germination with Observation on Several Crop Plants. Soil Science Society of America Proceedings, 13, 224-226. 
https://doi.org/10.2136/sssaj1949.036159950013000C0039x

[17] Cook, R.E. (1979) Patterns of Juvenile Morbidity and Recruitment in Plants. In: Solbrig, O.T., Jain, S., Johnson, G.B. and Raven, P.H., Eds., Topics in Plant Population Biology, Columbia University Press, Los Angeles, 207-301. https://doi.org/10.1007/978-1-349-04627-0_10

[18] Jones, R.A. (1986) High Salt Tolerance Potential in Lycopersicon Species during Germination. Euphytica, 35, 575-582. https://doi.org/10.1007/BF00021866

[19] Maas, E.V., Poss, J.A. and Hoffman, G.J. (1986) Salt Tolerance of Plants. Applied Agricultural Research, 1, 12-26.

[20] Almansouri, M., Kinet, J.-M. and Lutts, S. (2001) Effect of Salt and Osmotic Stresses on Germination in Durum Wheat (Triticum durum Desf.). Plant and Soil, 231, 243-254. https://doi.org/10.1023/A:1010378409663

[21] Esechie, H.A. (1994) Interaction of Salinity and Temperature on the Germination of Sorghum. Journal of Agronomy and Crop Science, 172, 194-199. https://doi.org/10.1111/j.1439-037X.1994.tb00166.x

[22] Shen, Y., Li, Y. and Yan, S.G. (2003) Effects of Salinity on Germination of Six Salt-Tolerant Forage Species and Their Recovery from Saline Conditions. New Zealand Journal of Agricultural Research, 46, 263-269. https://doi.org/10.1080/00288233.2003.9513552

[23] Saberi, M., Reza, M., Ghaleno, D., Sardo, M.S. and Tarnian, F. (2012) Influence of Salinity and Temperature on Germination of Trifolium repens. Modern Applied Science, 6, 34-41. https://doi.org/10.5539/mas.v6n9p34

[24] Li, R., Shi, F., Fukuda, K. and Yang, Y. (2010) Effects of Salt and Alkali Stresses on Germination, Growth, Photosynthesis and Ion Accumulation in Alfalfa (Medicago sativa L.). Soil Science and Plant Nutrition, 56, 725-733. https://doi.org/10.1111/j.1747-0765.2010.00506.x

[25] Shaheen, R. and Hood-Nowotny, R.C. (2005) Effect of Drought and Salinity on Carbon Isotope Discrimination in Wheat Cultivars. Plant Science, 168, 901-909. https://doi.org/10.1016/j.plantsci.2004.11.003

[26] Richards, R.A. (1978) Variation between and within Species of Rapeseed (Brassica campestris and B. napus) in Response to Drought Stress. III. Physiological and Physicochemical Characters. Australian Journal of Agricultural Research, 29, 491-501. https://doi.org/10.1071/AR9780491

[27] Khakwani, A.A., Dennett, M.D. and Munir, M. (2011) Drought Tolerance Screening of Wheat Varieties by Inducing Water Stress Conditions. Songklanakarin Journal of Science and Technology, 33, 135-142.

[28] Agili, S., Nyende, B., Ngamau, K. and Masinde, P. (2012) Selection, Yield Evaluation, and Drought Tolerance Indices of an Orange-Flesh Sweet Potato (Ipomoea batatas Lam.) Hybrid Clone. Journal of Nutrition and Food Sciences, 2, 1-8.

[29] Hohl, M. and Schopfer, P. (1991) Water Relations of Growing Maize Coleoptiles. Comparison between Mannitol and Polyethylene Glycol 6000 as External Osmotica for Adjusting Turgor Pressure. Plant Physiology, 95, 716-722. https://doi.org/10.1104/pp.95.3.716

[30] Kulkarni, M. and Deshpande, U. (2007) In Vitro Screening of Tomato Genotypes for Drought Resistance Using Polyethylene Glycol. African Journal of Biotechnolo$g y$, 6, 691-696.

[31] Farsiani, A. and Ghobadi, M.E. (2009) Effects of PEG and NaCl Stress on Two Cultivars of Corn (Zeamays L.) at Germination and Early Seedling Stages. World 
Academy of Science, Engineering and Technology, 57, 382-385.

[32] Gharoobi1, B., Ghorbani, M. and Nezhad, M.G. (2012) Effects of Different Levels of Osmotic Potential on Germination Percentage and Germination Rate of Barley, Corn and Canola. Iranian Journal of Plant Physiology, 2, 413-417.

[33] KalefetoglluMacar, T., Tura, O. and Ekmekci, Y. (2009) Effect of Water Deficit Induced by PEG and $\mathrm{NaCl}$ Onchickpea (Cicer arieitinum L.) Cultivars and Lines at Early Seedling Stage. Gazi University Journal of Science, 22, 5-14.

[34] Khazaie, H., Kafi, M. and Masumi, A. (2008) Physiological Effects of Stress Induced by Polyethylene Glycol on Germination of Chickpea Genotypes. Journal of Agronomic Research of Iran, 2, 453. 